\title{
Pengaruh Social Media Marketing dan Product Quality Terhadap Purchase Decision dengan Purchase Intention sebagai Interverning pada Produk Jims Honey (Studi pada Masyarakat Kebumen)
}

\author{
Endah Setiawati ${ }^{1}$, Gunarso Wiwoho ${ }^{2}$ \\ 1,2Universitas Putra Bangsa \\ esetiawati577@gmail.com ${ }^{1}$
}

\section{ARTICLE INFO}

Article History:

Received: June $19^{\text {th }} 2021$

Accepted: June $21^{\text {st }} 2021$

Published: June 21 2021

Keywords:

Social Media Marketing,

Product Quality, Purchase

Intention, Purchase

Decision

\begin{abstract}
Perkembangan bisnis di dunia Industri fashion terus mengalami perubahan dalam periode waktu yang sangat singkat. Penelitian ini bertujuan untuk menguji dan menganalisis pengaruh social media marketing, dan product quality terhadap purchase decision melalui purchase intention produk Jims Honey pada masyarakat di Kabupaten Kebumen. Teknik pengumpulan data dengan menggunakan teknik non probability sampling, sampel dalam penelitian ini sebanyak 100 responden. Hipotesis diuji dengan bantuan SPSS 25 for windows. Metode yang digunakan dalam penelitian ini adalah metode kuantitatif menggunakan analisis jalur. Hasil penelitian ini yaitu: (1) social media marketing $\left(\mathrm{X}_{1}\right)$ berpengaruh signifikan terhadap purchase intention $\left(\mathrm{Y}_{1}\right)$; $(2)$ product quality $\left(\mathrm{X}_{2}\right)$ berpengaruh signifikan terhadap purchase intention $\left(\mathrm{Y}_{1}\right)$ dan juga berpengaruh signifikan terhadap purchase decision $\left(\mathrm{Y}_{2}\right) ;(3)$ social media marketing $\left(\mathrm{X}_{1}\right)$ tidak berpengaruh terhadap purchase decision $\left(\mathrm{Y}_{2}\right)$; (4) social media marketing $\left(\mathrm{X}_{1}\right)$ dan product quality $\left(\mathrm{X}_{2}\right)$ secara tidak langsung masing-masing berpengaruh terhadap purchase decision $\left(\mathrm{Y}_{2}\right)$ melalui purchase intention $\left(\mathrm{Y}_{1}\right)$.
\end{abstract}

\section{Pendahuluan}

Seiring dengan munculnya industri 4.0 yang semakin global mengakibatkan perubahan yang cukup signifikan bagi berbagai negara dimana konsep industri 4.0 menuntut perubahan pola perilaku menjadi cepat dan luar biasa. Perkembangan arus globalisasi bisnis pada saat ini turut mengalami perkembangan dengan sangat pesat, sehingga berbagai industri memerlukan sebuah konsep inovasi dan kreativitas dalam menjalankan bisnis untuk menunjukan eksistensinya, sehingga agar mampu bersaing secara internasional di dalam ketatnya persaingan antar dunia bisnis.

Perkembangan trend fashion yang semakin beragam menjadi budaya baru untuk masyarakat yang sangat memperhatikan penampilannya agar terlihat menarik, stylish dan trendy. Salah satu bisnis fashion yang menyediakan kebutuhan manusia dalam menunjang penampilannya di Indonesia adalah Jims Honey. Jims Honey merupakan salah satu brand nasional yang menyediakan produk aksesoris berupa jam tangan, tas, dan produk unggulan lainnya yang 
didesain secara khusus sebagai penunjang penampilan. Pangsa pasar Jims Honey yang luas dengan memanfaatkan social media marketing dengan produk yang berkualitas untuk menjaga minat beli konsumen supaya tetap setia menggunakan Jims Honey.

Pada saat ini bisnis fashion Jims Honey meskipun tergolong baru mampu menguasai pasar di Indonesia. Jims Honey dalam menjalankan bisnisnya hanya mengandalkan digital marketing melalui sosial media sebagai sarana pengenalan dan penjualan produk sehingga produk Jims Honey tidak akan ditemui pada swalayan maupun mall. Berdasarkan hasil mini riset yang dilakukan oleh peneliti dengan 30 responden pada masyarakat Kebumen diperoleh hasil bahwa faktor yang mempengaruhi purchase decision terhadap produk Jims Honey 25,49\% memilih karena promosi yang menarik pada sosial media, 25,49\% karena kualitas produk yang dimiliki, 13,73\% atas kesesuaian harga terhadap produk, 13,73\% karena citra merek produk, 15,69\% karena desain produk, dan 9,1\% atas kemudahan transaksi.

Tabel 1 Faktor yang Mempengaruhi Purchase Decision Produk Jims Honey

\begin{tabular}{lcc}
\hline \multicolumn{1}{c}{ Faktor } & Jumlah & Presentase \\
\hline Sosial Media Marketing & 13 & $25,49 \%$ \\
Kualitas Produk & 13 & $25,49 \%$ \\
Harga & 7 & $13,73 \%$ \\
Desain Produk & 8 & $15,69 \%$ \\
Citra Merek & 7 & $13,73 \%$ \\
Kemudahan Transaksi & 3 & $5,88 \%$ \\
\hline \multicolumn{1}{c}{ Jumlah } & $\mathbf{5 1}$ & $\mathbf{1 0 0} \%$ \\
\hline
\end{tabular}

Peran sosial media dalam kehidupan sehari-hari sangat penting pada saat ini dimana dengan adanya situasi perkembangan transformasi digital keberadaan sosial media menjadi hal yang selalu ada pada setiap individu untuk berkomunikasi dan menggali informasi. Hal ini tentunya akan mendorong perubahan perilaku konsumen dalam proses transaksi. Menurut Weinberg dalam Mileva dan Fauzi (2018) social media marketing adalah sebuah proses yang mendorong individu untuk melakukan promosi melalui situs web, produk, atau layanan mereka melalui saluran sosial online dan untuk berkomunikasi dengan memanfaatkan komunitas yang jauh lebih besar yang memiliki kemungkinan lebih besar untuk melakukan pemasaran daripada melalui saluran periklanan tradisional. Hasil penelitian yang dilakukan oleh Wahyu dan Agus (2020) menunjukan bahwa sosial media marketing berpengaruh positif terhadap purchase decision, maka semakin baik social media marketingnya maka keputusan pembelian akan semakin baik.

Selain faktor sosial media marketing yang berpengaruh dalam konsumen Jims Honey melakukan pembelian yaitu product quality atau kualitas produk. Hasil penelitian yang dilakukan oleh Arifai dan Trihandayani (2017) menunjukan hasil bahwa variabel kualitas produk mempengaruhi keputusan pembelian, oleh karena itu jika kualitas produk menurun maka akan mempengaruhi keputusan pembelian pada konsumen.

Purchase decision atau keputusan pembelian adalah keputusan konsumen yang meliputi keputusan konsumen mengenai apa yang akan dibeli, apakah akan melakukan pembelian atau tidak, kapan membeli dimana membeli dan bagaimana cara membayarnya (Sumarwan, 2014). Purchase intention atau minat beli adalah sebuah ketertarikan konsumen akan sebuah 
produk atau jasa yang ditawarkan, minat beli dapat menjadi prediksi terhadap keputusan pembelian (purchase decision) pada masa yang akan datang.

\section{Kajian Teori dan Telaah Literatur}

\section{Social Media Marketing $\left(\mathrm{X}_{1}\right)$}

Gunelius (2011: 10) mengartikan sosial media marketing sebagai bentuk pemasaran yang dilakukan secara langsung maupun tidak langsung menggunakan web sosial seperti blogging, micro blogging dan jejaring sosial untuk membangun pengakuan, kesadaran dan ingatan terhadap suatu merek (bisnis), produk, personal atau entitas lainnya. Menurut Weinberg dalam Mileva dan Fauzi (2018) social media marketing adalah sebuah proses yang mendorong individu untuk melakukan promosi melalui situs web, produk, atau layanan mereka melalui saluran sosial online dan untuk berkomunikasi dengan memanfaatkan komunitas yang jauh lebih besar yang memiliki kemungkinan lebih besar untuk melakukan pemasaran daripada melalui saluran periklanan tradisional.

Sedangkan menurut teori (Hoffman \& Novak, 2017) media sosial dapat menjadi media promosi yang paling efektif dan efisien, sebab media sosial memberikan kemudahan kepada para penggunanya dalam memperoleh informasi serta memberikan pelayanan yang baik.

Menurut Gunelius (2011:59-62) terdapat empat elemen yang dijadikan sebagai variabel kesuksesan social media marketing yaitu: Content Creation; Content Sharing; Connecting; dan Community Building. Indikator social media marketing menurut Jayson DeMers (2014), yaitu:

1) Tulisan yang berkualitas

2) Foto yang menarik

3) Frekuensi keaktifan postingan

\section{Product Quality $\left(\mathrm{X}_{2}\right)$}

Menurut Kotler dan Keller (2012:143) kualitas produk didefinisikan sebagai evaluasi menyeluruh pelanggan atas kebaikan kinerja produk. Sedangkan menurut Kotler dan Amstrong dalam Weenas (2013) mendefinisikan kualitas produk sebagai kemampuan suatu produk untuk melaksanakan fungsinya, meliputi daya tahan keandalan, ketepatan, kemudahan operasi dan perbaikan serta atribut bernilai lainnya.

Kualitas adalah kecocokan untuk digunakan, pemenuhan tuntutan, kulalitas ditentukan oleh sekumpulan kegunaan atau fungsinya, termasuk didalamnya daya tahan, ketergantungan pada produk atau komponen lain, ekslusive, kenyamanan, wujud luar (warna, bentuk, pembungkus dan sebagainya) (Kotler dan Keller, 2012).

Menurut Russel dalam Harsalim, R.R. (2015) kualitas (quality) sangat penting bagi organisasi karena : meningkatkan reputasi perusahaan, penurunan biaya, peningkatan pangsa pasar, pertanggungjawaban produk, dan dampak internasional. Indikator product quality menurut Fandi Tjiptono dalam Arifai, Trihandayani, Z. (2018), yaitu:

1) Kinerja (Performance)

2) Keistimewaan tambahan atau fitur

3) Kehandalan 
4) Daya tahan

5) Kesesuaian dengan spesifikasi

6) Estetika

7) Kualitas yang dipersepsikan

8) Dimensi kemudahan perbaikan

\section{Purchase Intention $\left(\mathrm{Y}_{1}\right)$}

Menurut Kotler dan Keller (2016:198) Purchase Intention merupakan bentuk dari perilaku dari konsumen yang berkeinginan untuk membeli atau memilih sebuah produk yang didasari oleh pengalaman, penggunaan dan keinginannya pada suatu produk. Menurut Hosein (2012), purchase intention atau minat membeli dapat dianggap sebagai salah satu komponen utama perilaku kognitif konsumen yang dapat menunjukan bagaimana seseorang bermaksud untuk membeli merek tertentu atau produk tertentu.

Menurut Hosein (2012) melalui penelitiannya mengemukakan tiga elemen dalam Purchase Intention, yaitu : (1) Interest, berbicara mengenai bagaimana seseorang memiliki perasaan secara personal terhadap produk dan merek yang ada; (2) Attending adalah keberadaan fisik secara aktual seseorang, entah dalam grup maupun sendirian yang mencakup tujuan seseorang tersebut pada lokasi tempat produk berada; (3) Information, berhubungan dengan data yang didapatkan saat berada di lokasi produk yang dapat menambah pengetahuan pada proses pemikiran mengenai minat terhadap produk.

Purchase intention juga dapat diartikan sebagai kemungkinan konsumen untuk melakukan pembelian pada produk atau brand (Keller, 2013). Menurut Kotler dalam Karundeng (2019) Minat beli konsumen memiliki tahap-tahap yang bisa dilihat melalui model AIDA (attention, interest, desire, dan action). Indikator Purchase Intention menurut Ferdinand (2006) sebagai berikut:
1) Minat Transaksional
2) Minat Referensial
3) Minat Preferensial
4) Minat Eksploratif

\section{Purchase Decision $\left(\mathrm{Y}_{2}\right)$}

Menurut Sumarwan (2014 : 377) keputusan pembelian adalah keputusan konsumen yang meliputi keputusan konsumen mengenai apa yang akan dibeli, apakah akan melakukan pembelian atau tidak, kapan membeli dimana membeli dan bagaimana cara membayarnya. Sedangkan menurut Kotler (2012) keputusan pembelian adalah suatu tahap dimana konsumen telah memiliki pilihan dan siap untuk melakukan pembelian atau pertukaran antara uang dan janji untuk membayar dengan hak kepemilikan atau penggunaan suatu barang atau jasa.

Menurut Dharmmesta dan Handoko (2012:102) keputusan pembelian memiliki struktur sebanyak tujuh komponen yang terdiri dari: (1) keputusan tentang jenis produk; (2) keputusan tentang bentuk produk; (3) keputusan tentang merek; (4) keputusan tentang penjualnya; (5) keputusan tentang jumlah produk; (6) keputusan tentang waktu pembelian; dan (7) keputusan tentang cara pembayaran. Indikator keputusan pembelian menurut Kotler (2012), sebagai berikut: 
1) Kemantapan pada sebuah produk

2) Kebiasaan dalam membeli produk

3) Merekomendasikan kepada orang lain

4) Melakukan pembelian ulang

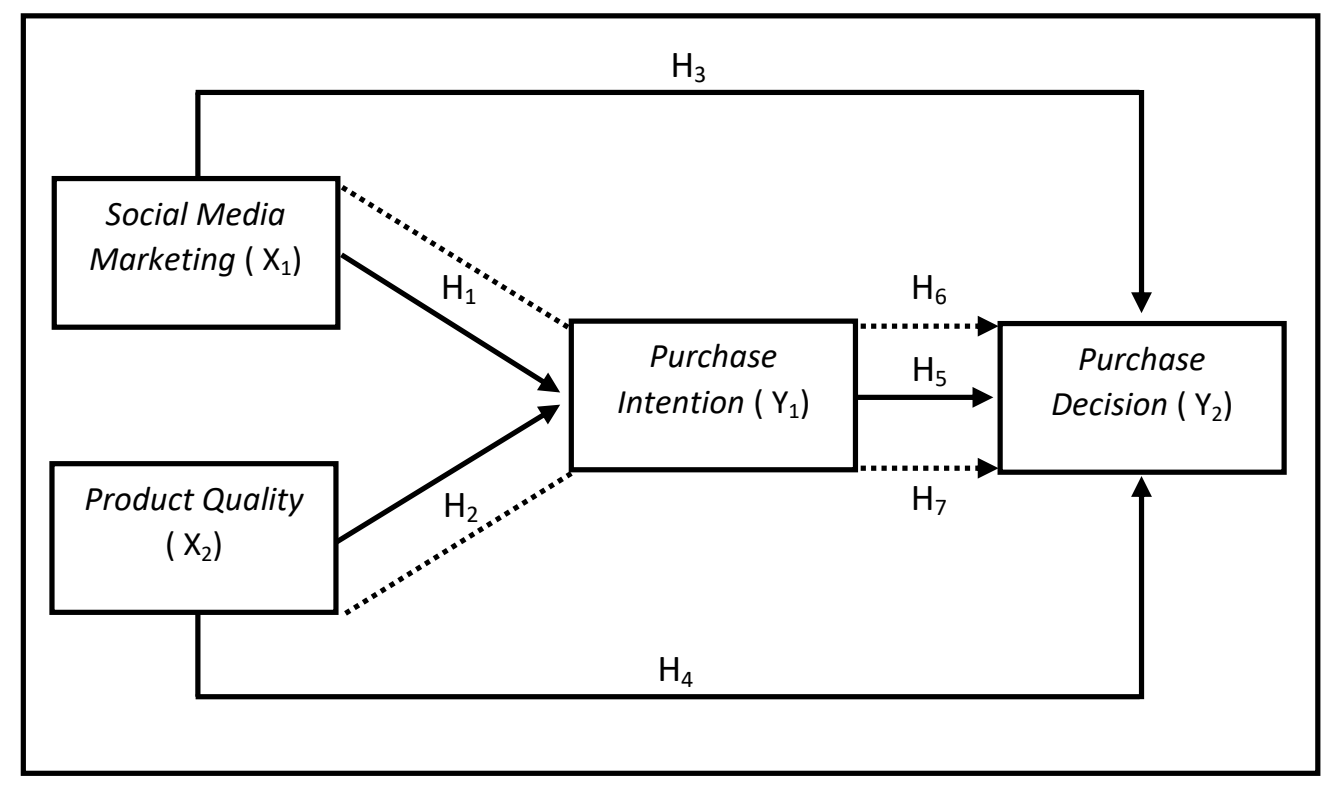

Gambar 1 Kerangka Pemikiran Penelitian

$\mathrm{H}_{1}$ :Terdapat pengaruh signifikan variabel $\mathrm{X}_{1}$ terhadap variabel $Y_{1}$.

$\mathrm{H}_{2}$ :Terdapat pengaruh signifikan variabel $X_{2}$ terhadap variabel $Y_{2}$.

$\mathrm{H}_{3}$ :Terdapat pengaruh signifikan variabel $X_{1}$ terhadap variabel $Y_{2}$.

$\mathrm{H}_{4}$ :Terdapat pengaruh signifikan variabel $X_{2}$ terhadap variabel $Y_{2}$.

$\mathrm{H}_{5}$ :Terdapat pengaruh signifikan variabel $Y_{1}$ terhadap variabel $Y_{2}$.

$\mathrm{H}_{6}$ :Terdapat pengaruh $\mathrm{X}_{1}$ terhadap $\mathrm{Y}_{2}$ melalui $\mathrm{Y}_{1}$.

$\mathrm{H}_{7}$ :Terdapat pengaruh $\mathrm{X}_{2}$ terhadap $\mathrm{Y}_{2}$ melalui $\mathrm{Y}_{1}$.

\section{Metode Penelitian}

Objek dalam penelitian ini adalah Purchase Decision sebagai variabel terikat (dependent variable), sedangkan Social Media Marketing, dan Product Quality sebagai variabel bebas (independent variable), dengan Purchase Intention sebagai variabel intervening.Dalam Penelitian ini yang menjadi subjek adalah masyarakat Kota Kebumen yang pernah melakukan keputusan pembelian produk Jims Honey.

Populasi dalam penelitian ini adalah masyarakat Kota Kebumen yang merupakan konsumen produk Jims Honey. Peneliti mengambil sampel sebanyak 100 orang. Teknik sampel dalam penelitian ini adalah metode non probability sampling dengan teknik purposive sampling.

Dalam perhitungan pengolahan data, peneliti menggunakan alat bantu berupa program aplikasi komputer SPSS for windows 25,0. Adapun analisis yang digunakan yaitu Uji Instrumen meliputi (Uji Validitas dan Uji Reliabilitas), Uji Asumsi Klasik meliputi (Uji Multikolinearitas, Uji Heteroskedastisitas, dan Uji Normalitas), Uji Hipotesis meliputi (Uji Parsial (Uji t), Koefisien Determinasi), Analisis Korelasi, Analisis Jalur dan Uji Sobel. 


\section{Hasil dan Pembahasan}

\section{Analisis Deskriptif}

Berdasarkan data yang diperoleh dari hasil penelitian yang dilakukan terhadap 100 orang, maka dapat diidentifikasi mengenai karakteristik responden sebagai berikut:

Tabel 2 Responden berdasarkan Jenis Kelamin

\begin{tabular}{clcc}
\hline No & Jenis Kelamin & Frekuensi & Presentase \\
\hline 1 & Perempuan & 94 & $94 \%$ \\
2 & Laki-laki & 6 & $6 \%$ \\
\hline & Jumlah & 100 & $100 \%$ \\
\hline
\end{tabular}

Sumber: Data primer diolah, 2021.

Berdasarkan tabel 1 menunjukan bahwa responden yang berjenis kelamin perempuan berjumlah 94 orang atau $94 \%$, dan jenis kelamin laki-laki berjumlah 6 orang atau $6 \%$.

Tabel 3 Responden berdasarkan Usia

\begin{tabular}{cccc}
\hline No & Usia & Frekuensi & Presentase \\
\hline 1. & $17-22$ tahun & 58 & $58 \%$ \\
2. & $23-28$ tahun & 40 & $40 \%$ \\
3. & $29-34$ tahun & 1 & $1 \%$ \\
4. & $35-40$ tahun & 1 & $1 \%$ \\
\hline \multicolumn{2}{c}{ Jumlah } & 100 & $100 \%$ \\
\hline Sumber: Data primer diolah, 2021.
\end{tabular}

Berdasarkan tabel 2 menunjukan bahwa responden yang berusia 17-22 tahun berjumlah 58 atau 58\%, usia 23-28 tahun berjumlah 40 atau 40\%, usia 29-34 tahun berjumlah 1 atau 1\%, dan usia 35-40 tahun berjumlah 1 atau $1 \%$.

Tabel 4 Responden berdasarkan Pekerjaan

\begin{tabular}{clcc}
\hline No & \multicolumn{1}{c}{ Usia } & Frekuensi & Presentase \\
\hline 1. & Mahasiswa/Pelajar & 61 & $61 \%$ \\
2. & Karyawan Swasta & 4 & $4 \%$ \\
3. & Pegawai Negri Sipil (PNS) & 2 & $2 \%$ \\
4. & Wirausaha & 19 & $19 \%$ \\
5. & Ibu Rumah Tangga & 6 & $6 \%$ \\
6. & Lainnya & 8 & $8 \%$ \\
\hline \multicolumn{2}{r}{ Jumlah } & 100 & $100 \%$ \\
\hline
\end{tabular}

Sumber: Data primer diolah, 2021.

Berdasarkan tabel 3 dapat diketahui bahwa dari 100 responden yang dijadikan sampel dengan berdasarkan pekerjaan Mahasiswa/Pelajar berjumlah 61 atau 61\%, Karyawan Swasta berjumlah 19 atau 19\%, Pegawai Negri Sipil (PNS) berjumlah 2 atau 2\%, Wirausaha berjumlah 4 atau 4\%, Ibu Rumah Tangga berjumlah 6 atau 6\% dan Pekerjaan Lainnya berjumlah 8 atau $8 \%$. 
Tabel 5 Responden berdasarkan Pendapatan

\begin{tabular}{cccc}
\hline No & Pendapatan & Frekuensi & Presentase \\
\hline 1. & $<1.000 .000$ & 67 & $67 \%$ \\
2. & $1.000 .000-2.000 .000$ & 28 & $28 \%$ \\
3. & $>3.000 .000$ & 5 & $5 \%$ \\
\hline \multicolumn{2}{c}{ Jumlah } & 100 & $100 \%$ \\
\hline Sumber: Data primer diolah, 2021. & &
\end{tabular}

Berdasarkan tabel 4 dapat diketahui bahwa dari 100 responden yang dijadikan sampel dengan berdasarkan pendapatan $<1.000 .000$ berjumlah 67 atau $67 \%, 1.000 .000-2.000 .000$ berjumlah 28 atau $28 \%$, dan $>3.000 .000$ berjumlah 5 atau $5 \%$.

\section{Analisis Statistik}

Analisis statistic dalam penelitian ini menggunakan data kuantitatif dengan menggunakan kuesioner sebagai alat bantu analisis yang berasal dari 100 responden yang merupakan konsumen produk Jims Honey.

\section{Uji Validitas dan Uji Reliabilitas}

\section{Uji Validitas}

Uji validitas digunakan untuk mengukur sah atau valid tidaknya suatu kuesioner. Suatu kuesioner dikatakan valid jika pertanyaan pada kuesioner mampu untuk mengungkapkan sesuatu yang akan diukur oleh kuesioner tersebut (Ghozali, 2013:52). Untuk mengukur validitas dalam penelitian ini digunakan pearson correlation dengan tariff signifikansi $5 \%$ atau 0,05 dan $r$ tabel 0,197.

\section{Variabel Social Media Marketing $\left(\mathrm{X}_{1}\right)$}

Hasil uji validitas variabel social media marketing dapat dijelaskan sebagai berikut:

Tabel 6 Hasil Uji Validitas Social Media Marketing

\begin{tabular}{ccccc}
\hline Butir & rhitung & $\mathrm{r}_{\text {tabel }}$ & Signifikan & Keterangan \\
\hline 1 & 0,807 & 0,197 & 0,000 & Valid \\
2 & 0,806 & 0,197 & 0,000 & Valid \\
3 & 0,791 & 0,197 & 0,000 & Valid \\
\hline Sumber: Data primer diolah, 2021 & & &
\end{tabular}

Berdasarkan tabel 5, hasil uji validitas pada instrument variabel social media marketing menunjukan bahwa nilai korelasi pada kolom rtabel 0,197 dengan tingkat signifikansi kurang dari 0,05 sehingga dapat disimpulakn bahwa semua butir pernyataan dinyatakan valid. 
Variabel Product Quality $\left(\mathrm{X}_{2}\right)$

Hasil uji validitas variabel product quality dapat dijelaskan sebagai berikut:

Tabel 7 Hasil Uji Validitas Product Quality

\begin{tabular}{ccccc}
\hline Butir & $\mathrm{r}_{\text {hitung }}$ & $\mathrm{r}_{\text {tabel }}$ & Signifikan & Keterangan \\
\hline 1 & 0,691 & 0,197 & 0,000 & Valid \\
2 & 0,610 & 0,197 & 0,000 & Valid \\
3 & 0,766 & 0,197 & 0,000 & Valid \\
4 & 0,680 & 0,197 & 0,000 & Valid \\
5 & 0,722 & 0,197 & 0,000 & Valid \\
6 & 0,711 & 0,197 & 0,000 & Valid \\
7 & 0,687 & 0,197 & 0,000 & Valid \\
8 & 0,627 & 0,197 & 0,000 & Valid \\
\hline Sumber: Data primer diolah, 2021 & & &
\end{tabular}

Berdasarkan tabel 6, hasil uji validitas pada instrument variabel product quality menunjukan bahwa nilai korelasi pada kolom rtabel 0,197 dengan tingkat signifikansi kurang dari 0,05 sehingga dapat disimpulakn bahwa semua butir pernyataan dinyatakan valid.

Variabel Purchase Intention $\left(\mathrm{Y}_{1}\right)$

Hasil uji validitas variabel purchase intention dapat dijelaskan sebagai berikut:

Tabel 8 Hasil Uji Validitas Purchase Intention

\begin{tabular}{ccccc}
\hline Butir & $\mathrm{r}_{\text {hitung }}$ & $\mathrm{r}_{\text {tabel }}$ & Signifikan & Keterangan \\
\hline 1 & 0,575 & 0,197 & 0,000 & Valid \\
2 & 0,868 & 0,197 & 0,000 & Valid \\
3 & 0,831 & 0,197 & 0,000 & Valid \\
4 & 0,841 & 0,197 & 0,000 & Valid \\
\hline
\end{tabular}

Sumber: Data primer diolah, 2021

Berdasarkan tabel 7, hasil uji validitas pada instrument variabel purchase inteniton menunjukan bahwa nilai korelasi pada kolom rtabel 0,197 dengan tingkat signifikansi kurang dari 0,05 sehingga dapat disimpulkan bahwa semua butir pernyataan dinyatakan valid.

Variabel Purchase Decision $\left(\mathrm{Y}_{2}\right)$

Hasil uji validitas variabel purchase decision dapat dijelaskan sebagai berikut:

Tabel 9 Hasil Uji Validitas Purchase Decision

\begin{tabular}{ccccc}
\hline Butir & $r_{\text {hitung }}$ & rtabel & Signifikan & Keterangan \\
\hline 1 & 0,694 & 0,197 & 0,000 & Valid \\
2 & 0,755 & 0,197 & 0,000 & Valid \\
3 & 0,785 & 0,197 & 0,000 & Valid \\
4 & 0,798 & 0,197 & 0,000 & Valid \\
\hline
\end{tabular}

Sumber: Data primer diolah, 2021

Berdasarkan tabel 8, hasil uji validitas pada instrument variabel purchase decision menunjukan bahwa nilai korelasi pada kolom rtabel 0,197 dengan tingkat signifikansi kurang dari 0,05 sehingga dapat disimpulakn bahwa semua butir pernyataan dinyatakan valid. 


\section{Uji Reliabilitas}

Uji reliabilitas digunakan untuk mengukur sejauh mana suatu alat ukur dapat dipercaya atau diandalkan. Instrumen pada penelitian dikatakan reliabel, jika nilai Cronbach's Alpha lebih besar dari 0,60 (Ghozali, 2009).

Hasil uji reliabilitas dapat dijelaskan sebagai berikut:

Tabel 10 Hasil Uji Reliabilitas

\begin{tabular}{lccc}
\hline \multicolumn{1}{c}{ Variabel } & Crobach's Alpa & Batas Frekuensi & Keterangan \\
\hline Social Media Marketing & 0,718 & 0,60 & Reliabel \\
Product Quality & 0,838 & 0,60 & Reliabel \\
Purchase Intention & 0,793 & 0,60 & Reliabel \\
Purchase Decision & 0,752 & 0,60 & Reliabel \\
\hline
\end{tabular}

Sumber: Data primer diolah, 2021

Berdasarkan tabel 8 diatas, menunjukan bahwa hasil uji reliabilias variabel social media marketing $\left(\mathrm{X}_{1}\right)$, variabel product quality $\left(\mathrm{X}_{2}\right)$, variabel purchase intention $\left(\mathrm{Y}_{1}\right)$, dan variabel purchase decision $\left(\mathrm{Y}_{2}\right)$ diatas 0,60 sehingga dapat disimpulkan semua variabel reliabel.

\section{Uji Asumsi Klasik}

\section{Uji Multikolinearitas}

Model regresi dikatakan bebas dari multikolinearitas apabila memiliki nilai VIF 10 dan mempunyai angka tolerance 0,1 .

Berikut hasil uji multikolinearitas substruktural 1:

Tabel 11 Hasil Uji Multikolinearitas Subtruktural 1

\begin{tabular}{lcc}
\hline \multicolumn{1}{c}{ Model } & \multicolumn{2}{c}{ Collinearity Statistics } \\
\cline { 2 - 3 } & Tolerance & VIF \\
\hline Social Media Marketing & 0,817 & 1,224 \\
Product Quality & 0,817 & 1,224 \\
\hline
\end{tabular}

Sumber: Data primer diolah, 2021

Berdasarkan tabel 9, menunjukan bahwa hasil uji multikolonieritas substructural 1, dengan variabel social media marketing dan product quality mempunyai nilai tolerance $>0,10$ dan nilai VIF (Variance Inflaction Factor) < 10,0, sehingga dapat disimpulakan bahwa tidak terjadi gejala multikolinearitas antar variabel independennya. 


\section{Uji Heteroskedastisitas}

Pengujian ini dilakukan untuk menguji apakah dalam sebuah model regresi terjadi ketidaksamaan varian dan residua disuatu pengamatan ke pengamatan yang lain. Hasil analisis uji heteroskedastisitas diperoleh sebagai berikut:

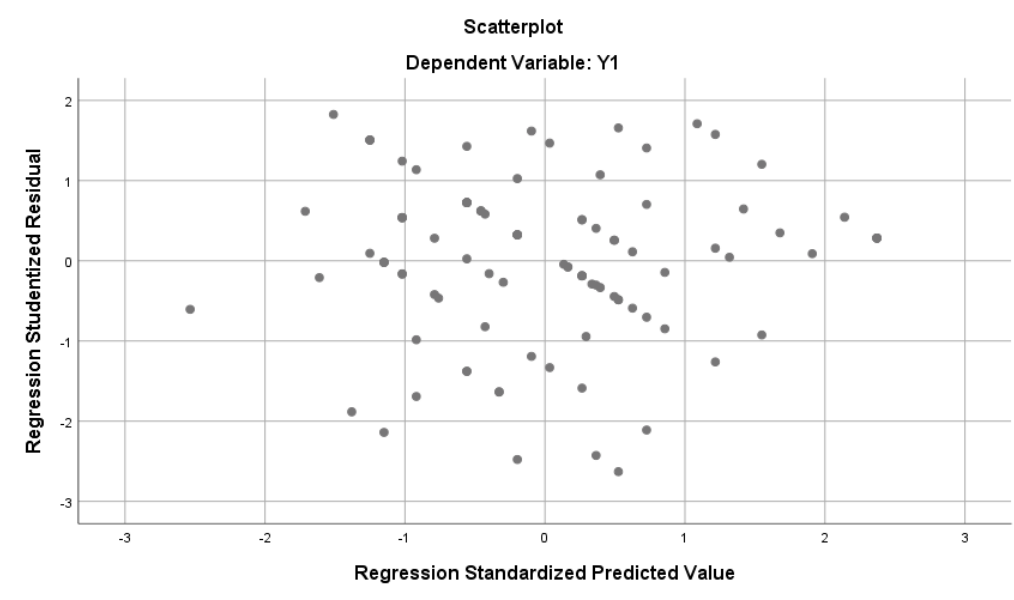

\section{Gambar 2 Hasil Uji Heteroskedastisitas Subtruktural 1}

Sumber: Data primer diolah, 2021

Berdasarkan gambar 2 scaterrplot menunjukan bahwa semua datanya menyebar dan tidak membentuk pola tertentu. sehingga dapat disimpulkan bahwa semua variable penelitian tersebut terbebas dari gejala heterokedastisitas.

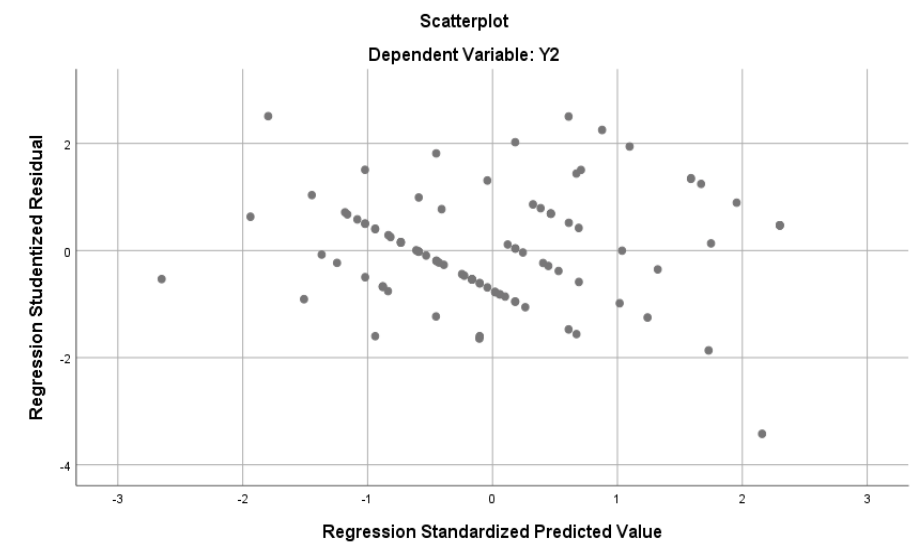

Gambar 3 Hasil Uji Heteroskedastisitas Subtruktural 2 Sumber: Data primer diolah, 2021

Berdasarkan gambar 3 scaterrplot menunjukan bahwa semua datanya menyebar dan tidak membentuk pola tertentu, sehingga dapat disimpulkan bahwa semua variable penelitian tersebut terbebas dari gejala heterokedastisitas.

\section{Uji Normalitas}

Uji normalitas bertujuan untuk menguji apakah sebuah model regresi, variable residual memiliki distribusi normal. Hasil analisis uji normalitas diperoleh sebagai berikut: 


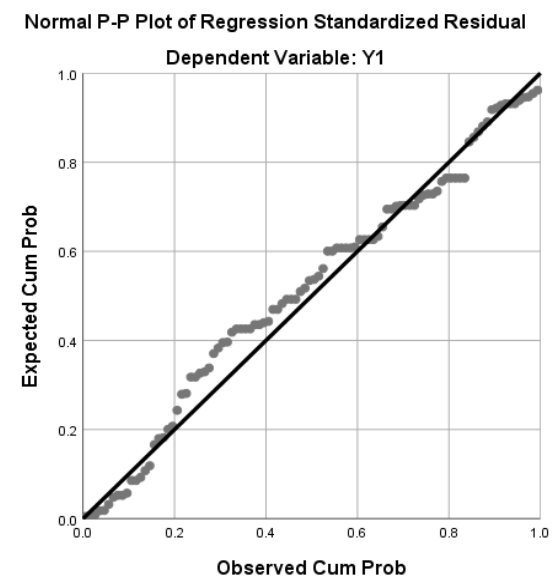

\section{Gambar 4 Hasil Uji Normalitas Subtruktural 1}

Sumber: Data primer diolah, 2021

Berdasarkan gambar 4, menunjukan bahwa hasil uji normalitas substruktural 1 terjadi titiktitik yang menyebar mengikuti garis diagonal dan berada tidak jauh dari garis diagonalnya, sehingga dapat disimpulkan bahwa hasil pengujian ini dinyatakan memiliki distribusi normal dan model regresi dalam penelitian ini memiliki asumsi normalitas.

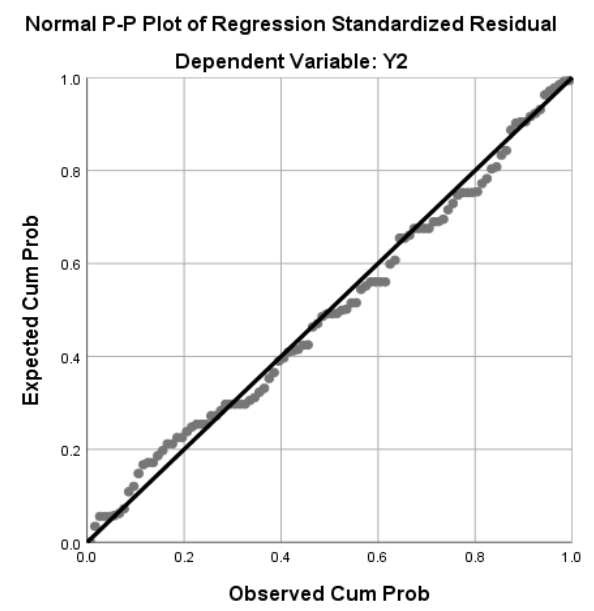

\section{Gambar 5 Hasil Uji Normalitas Subtruktural 2}

Sumber: Data primer diolah, 2021

Berdasarkan gambar 5, menunjukan bahwa hasil uji normalitas substruktural 2 terjadi titiktitik yang menyebar mengikuti garis diagonal dan berada tidak jauh dari garis diagonalnya, sehingga dapat disimpulkan bahwa hasil pengujian ini dinyatakan memiliki distribusi normal dan model regresi dalam penelitian ini memiliki asumsi normalitas.

\section{Uji Hipotesis}

\section{Uji Parsial (uji t)}

Uji parsial atau lebih sering disebut dengan uji $\mathrm{t}$ dalam penelitian ini digunakan untuk menunjukan satu variable bebas (independent) secara individual dalam menerangkan variable terikat (dependent). Tingkat signifikansi yang digunakan dalam penelitian ini sebesar 
$5 \%(a=0,05)$, jumlah sampel (n) sebanyak 100 , nilai $t_{\text {tabel }}$ subtruktural 1 sebesar 1,985. Berikut hasil uji parsial (uji t) subtruktural 1 :

Tabel 12 Hasil Uji Parsial (Uji t) Subtruktural 1

\begin{tabular}{|c|c|c|c|c|c|}
\hline \multirow{2}{*}{ Model } & \multicolumn{2}{|c|}{ Standardized Coefficient } & \multirow{2}{*}{$\frac{\text { Standardized Coefficient }}{\text { Beta }}$} & \multirow{2}{*}{$\mathbf{t}$} & \multirow{2}{*}{ Sig } \\
\hline & B & Std.Error & & & \\
\hline (Constant) & $-2,962$ & 1,358 & & $-2,181$ & 0,032 \\
\hline Social Media Marketing & 0,572 & 0,121 & 0,355 & 4,730 & 0,000 \\
\hline Product Quality & 0,366 & 0,053 & 0,520 & 6,929 & 0,000 \\
\hline
\end{tabular}

Sumber: Data primer diolah, 2021

Berdasarkan perhitungan, maka diperoleh nilai ttabel sebesar 1,985. Berikut hasil uji substruktural 2 :

Tabel 13 Hasil Uji Parsial (Uji t) Subtruktural 2

\begin{tabular}{lcccccc}
\hline \multirow{2}{*}{ Model } & \multicolumn{2}{c}{ Standardized Coefficient } & Standardized Coefficient & \multirow{2}{*}{ t } & Sig \\
\cline { 2 - 4 } & $\mathrm{B}$ & Std.Error & Beta & & 0,000 \\
(Constant) & 3,543 & 0,982 & & & & \\
Social Media Marketing & 0,075 & 0,095 & 0,063 & & 0,431 \\
Product Quality & 0,173 & 0,046 & 0,333 & & 3,798 & 0,000 \\
Purchase Intention & 0,348 & 0,072 & 0,470 & & 4,849 & 0,000 \\
\hline
\end{tabular}

Sumber: Data primer diolah, 2021

Berdasarkan tabel 10 dan 11, maka dapat dilihat uji t yang menunjukan hasil pengaruh tiap variabel dalam penelitian ini adalah sebagai berikut:

Tabel 14 Hasil Pengaruh Variabel

\begin{tabular}{|c|c|c|c|c|c|}
\hline No & Hipotesis & Variabel & thitung & $t_{\text {tabel }}$ & Konseptual \\
\hline 1 & $\mathrm{H}_{1}$ & $\begin{array}{l}\text { Social Media Marketing terhadap Purchase } \\
\text { Intention }\end{array}$ & 4,730 & 1,985 & Diterima \\
\hline 2 & $\mathrm{H}_{2}$ & Product Quality terhadap Purchase Intention & 6,929 & 1,985 & Diterima \\
\hline 3 & $\mathrm{H}_{3}$ & $\begin{array}{l}\text { Social Media Marketing terhadap Purchase } \\
\text { Decision }\end{array}$ & 0,791 & 1,985 & Ditolak \\
\hline 4 & $\mathrm{H}_{4}$ & Product Quality terhadap Purchase Decision & 3,798 & 1,985 & Diterima \\
\hline 5 & $\mathrm{H}_{5}$ & $\begin{array}{l}\text { Purchase Intention terhadap Purchase } \\
\text { Decision }\end{array}$ & 4,849 & 1,985 & Diterima \\
\hline
\end{tabular}

Sumber: Data primer diolah, 2021

\section{Koefisien Determinasi}

Koefisien dalam penelitian ini digunakan untuk mengukur besarnya kontribusi variabel independent dengan variabel dependen sehingga dapat diketahui variabel yang paling mempengaruhi variabel dependen. Berikut hasil pengujian koefisien determinasi substructural 1 dan 2:

Tabel 15 Hasil Koefisien Determinasi Subtructural 1

\begin{tabular}{rr|r|r|r}
\hline \multicolumn{1}{c}{ Model } & $\mathrm{R}$ & R Square & Adjusted R Square & Std. Error of the Estimate \\
\hline 1 & $.744^{\mathrm{a}}$ & .554 & .545 & 1.43634 \\
\hline
\end{tabular}

a. Predictors: (Constant), Product Quality (X2), Social Media Marketing (X1).

b. Dependent Variable: Purchase Intention (Y1)

Sumber: Data primer diolah, 2021 
Berdasarkan table 13, hasil pengujian ini menunjukan bahwa nilai Adjusted R2 subtruktural 1 sebesar 0,554 artinya sebesar 55,4\% variabel Purchase Intention dapat dijelaskan oleh variabel Social Media Marketing dan Product Quality, sedangkan sebesar 44,6\% (100\% - 55,4\%) dapat dijelaskan oleh variabel lain yang tidak ada dalam model penelitian ini.

Tabel 16 Hasil Koefisien Determinasi Subtructural 2

\begin{tabular}{rr|r|r|r}
\hline \multicolumn{1}{c}{ Model } & $\mathrm{R}$ & R Square & Adjusted R Square & Std. Error of the Estimate \\
\hline 1 & $.773^{\mathrm{a}}$ & .598 & .585 & 1.01386 \\
\hline
\end{tabular}

a. Predictors: (Constant), Purchase Intention (Y1), Product Quality (X2), Social Media Marketing (X1).

b. Dependent Variable: Purchase Decision (Y2)

Sumber: Data primer diolah, 2021

Berdasarkan table 14, hasil pengujian ini menunjukan bahwa nilai Adjusted R2 subtruktural 2 sebesar 0,598 artinya sebesar 59,8\% variabel Purchase Decision dapat dijelaskan oleh variabel Purchase Intention, Social Media Marketing, dan Product Quality sedangkan sebesar $40,2 \%(100 \%-59,8 \%)$ dapat dijelaskan oleh variabel lain yang tidak ada dalam model penelitian ini.

\section{Analisis Korelasi}

Analisis korelasi dalam penelitian ini, digunakan untuk menentukan kuatnya atau derajat hubungan linier antar variabel bebas yaitu variabel social media marketing dan product quality. Berikut hasil pengujian korelasi:

Tabel 17 Hasil Anlisis Korelasi

\begin{tabular}{llrr}
\hline & & Social Media Marketing & Product Quality \\
\hline Social Media Marketing & Pearson Correlation & 1,000 & $0,428^{* *}$ \\
& Sig. (2-tailed) & & 0,000 \\
& N & 100 & 100 \\
Product Quality & Pearson Correlation & $.428^{* *}$ & 1,000 \\
& Sig. (2-tailed) & 0,000 & \\
& N & 100 & 100 \\
\hline
\end{tabular}

**. Correlation is significant at the 0.01 level (2-tailed).

Sumber: Data primer diolah, 2021

Kekuatan antara dua variabel dapat dikreteriakan sebagai berikut (Sarwono,2007) :

Tabel 18 Interpretasi Koefisien Korelasi Nilai r

\begin{tabular}{cc}
\hline Interval Koefisien & Tingkat Hubungan \\
\hline 0 & Tidak ada korelasi antara dua variabel \\
$>0-0,25$ & Korelasi sangat lemah \\
$>0,25-0,5$ & Korelasi cukup \\
$>0,5-0,75$ & Korelasi kuat \\
$>0,75-0,99$ & Korelasi sangat kuat \\
1 & Korelasi sempurna \\
\hline
\end{tabular}

Sumber: Sarwono (2007), Analisis Jalur untuk Riset Bisnis dengan SPSS

Berdasarkan hasil korelasi tabel IV-18, sesuai dengan Sarwono (2007). Dapat disimpulkan bahwa hubungan social media marketing dan product quality memiliki nilai 0,428 sehingga dapat dikatakan memiliki hubungan korelasi cukup.

\section{Analisis jalur}




\section{Koefisien Jalur}

Koefisien jalur menunjukan kuatnya pengaruh variabel independen terhadap dependen. Koefisien jalur dapat dihitung dengan persamaan structural yang terdiri dari dua persamaan dimana X1, X2 adalah variabel independent, Y1 dan Y2 adalah variabel dependen, yang dirumuskan sebagai berikut:

\section{Subtruktural 1}

Y1 = PY1X1 + PY1X2 + €1

\section{Subtruktural 2}

$\mathrm{Y} 2=\mathrm{PY} 2 \mathrm{X} 1+\mathrm{PY} 2 \mathrm{X} 2+\mathrm{PY} 2 \mathrm{Y} 1+€ 2$

Keterangan:

$\mathrm{Y} 1$ : purchase intention

$\mathrm{Y} 2$ : purchase decision

$\mathrm{X} 1$ : social media marketing

$\mathrm{X} 2$ : product quality

$€ 1, € 2$ : nilai residu

Tabel 19 Hasil Uji Koefisien Jalur Subtruktural 1

\begin{tabular}{cccccc}
\hline \multirow{2}{*}{ Model } & $\begin{array}{c}\text { Unstandardized } \\
\text { Coefficient }\end{array}$ & $\begin{array}{c}\text { Standardized } \\
\text { Coefficient }\end{array}$ & $\mathrm{t}$ & Sig \\
\cline { 2 - 4 } & Std.Error & Beta & & \\
\hline (Constant) & 1,358 & & & $-2,181$ & 0,032 \\
Social Media Marketing & 0,121 & 0,355 & & 4,730 & 0,000 \\
Product Quality & 0,053 & 0,520 & & 6,929 & 0,000 \\
\hline
\end{tabular}

Sumber: Data primer diolah, 2021

Berdasarkan tabel 17, menunjukan hasil coefficients pada kolom standardized coefficients beta maka dapat dibuat persamaan regresi sebagai berikut:

$$
\begin{aligned}
& € 1=\sqrt{1-R}=\sqrt{1-0,744}=0,505 \\
& Y 1=0,355 X 1+0,520 \mathrm{X} 2+0,505 €_{1}
\end{aligned}
$$

Nilai-nilai P1, P2 dan $€ 1$ dapat dijelaskan sebagai berikut:

a. Koefisien regresi variabel social media marketing $(P 1)=0,355$

Koefisien regresi untuk X1 sebesar 0,355 artinya setiap penambahan 1 satuan pada variabel social media marketing (X1), maka akan menambah purchase intention sebesar 0,355 .

b. Koefisien regresi variabel product quality $(\mathrm{P} 2)=0,520$

Koefisien regresi untuk X2 sebesar 0,520 artinya setiap penambahan 1 satuan pada variabel product quality (X2), maka akan menambah purchase intention sebesar 0,520.

c. Nilai Residu $(€ 1)=0,505$

Nilai residu yang sebesar 0,505 menunjukan purchase intention yang tidak dapat dijelaskan oleh variabel social media marketing, dan product quality sebesar 0,505. 


\begin{tabular}{lccccc}
\hline \multirow{2}{*}{ Model } & $\begin{array}{c}\text { Unstandardized } \\
\text { Coefficient }\end{array}$ & $\begin{array}{c}\text { Standardized } \\
\text { Coefficient }\end{array}$ & $\mathbf{t}$ & Sig \\
\cline { 2 - 3 } \multicolumn{1}{c}{ (Constant) } & Std.Error & Beta & & & 0,000 \\
Social Media Marketing & 0,982 & & 0,063 & 0,791 & 0,431 \\
Product Quality & 0,095 & 0,333 & 3,798 & 0,000 \\
Purchase Intention & 0,046 & 0,470 & 4,849 & 0,000 \\
\hline Sumber: Data primer diolah, 2021 & 0,072 & & &
\end{tabular}

Berdasarkan tabel 18, menunjukan hasil coefficients pada kolom standardized coefficients beta maka dapat dibuat persamaan regresi sebagai berikut:

$$
\begin{aligned}
& € 1=\sqrt{1-R}=\sqrt{1-0,773}=0,476 \\
& \mathrm{Y} 2=0,063 \mathrm{X} 1+0,333 \mathrm{X} 2+0,470 \mathrm{Y} 1+0,476 €_{2}
\end{aligned}
$$

Nilai-nilai P1, P2, P3 dan $€ 2$ dapat dijelaskan sebagai berikut:

a. Koefisien regresi variabel social media marketing $(\mathrm{P} 1)=0,063$

Koefisien regresi untuk X1 sebesar 0,063 artinya setiap penambahan 1 satuan pada variabel social media marketing (X1), maka akan menambah purchase decision sebesar 0,063.

b. Koefisien regresi variabel product quality $(\mathrm{P} 2)=0,333$

Koefisien regresi untuk X2 sebesar 0,333 artinya setiap penambahan 1 satuan pada variabel product quality (X2), maka akan menambah purchase decision sebesar 0,333.

c. Koefisien regresi variabel purchase intention (P3) $=0,470$

Koefisien regresi untuk Y1 sebesar 0,470 artinya setiap penambahan 1 satuan pada variabel purchase intention (Y1), maka akan menambah purchase decision sebesar 0,470.

d. Nilai Residu $(€ 2)=0,476$

Nilai residu yang sebesar 0,476 menunjukan purchase decision yang tidak dapat dijelaskan oleh variabel social media marketing (X1), product quality (X2), dan purchase intention (Y1), diabaikan atau sama dengan 0 (nol).

\section{Perhitungan Pengaruh Masing-Masing Variabel}

\section{Pengaruh Langsung}

Perhitungan pengaruh langsung atau DE, digunakan formula sebagai berikut:

Pengaruh variabel social media marketing terhadap purchase intention

$\mathrm{X} 1 \rightarrow \mathrm{Y} 1 \quad=0,355$

Pengaruh variabel Product Quality terhadap Purchase Intention

$\mathrm{X} 2 \rightarrow \mathrm{Y} 1 \quad=0,520$

Pengaruh variabel Social Media Marketing terhadap Purchase Decision

$\mathrm{X} 1 \rightarrow \mathrm{Y} 2 \quad=0,063$

Pengaruh variabel Product Quality terhadap Purchase Intention

$\mathrm{X} 2 \rightarrow \mathrm{Y} 2=0,333$

Pengaruh variabel Purchase Intention terhadap Purchase Decision

$\mathrm{Y} 1 \rightarrow \mathrm{Y} 2=0,470$ 
Pengaruh variabel Social Media Marketing terhadap Purchase Decision melalui Purchase Intention

$$
\mathrm{X} 1 \rightarrow \mathrm{Y} 1 \rightarrow \mathrm{Y} 2 \quad=0,355 \times 0,470=0,167
$$

Pengaruh variabel Product Quality terhadap Purchase Decision melalui Purchase Intention $\mathrm{X} 2 \rightarrow \mathrm{Y} 1 \rightarrow \mathrm{Y} 2 \quad=0,333 \times 0,470=0,156$

\section{Pengaruh Total (Total Effect atau TE)}

Pengaruh variabel Social Media Marketing terhadap Purchase Decision melalui Purchase Intention

$\mathrm{X} 1 \rightarrow \mathrm{Y} 1 \rightarrow \mathrm{Y} 2 \quad=0,063+0,167=0,230$

Pengaruh variabel Product Quality terhadap Purchase Decision melalui Purchase Intention $\mathrm{X} 2 \rightarrow \mathrm{Y} 1 \rightarrow \mathrm{Y} 2 \quad=0,333+0,156=0,489$

Pengaruh variabel Social Media Marketing terhadap Purchase Decision

$\mathrm{X} 1 \rightarrow \mathrm{Y} 2 \quad=0,063$

Pengaruh variabel Product Quality terhadap Purchase Intention

$\mathrm{X} 2 \rightarrow \mathrm{Y} 2 \quad=0,333$

Pengaruh variabel Purchase Intention terhadap Purchase Decision

$\mathrm{Y} 1 \rightarrow \mathrm{Y} 2 \quad=0,470$

Berdasarkan hasil perhitungan maka pengaruh total terhadap penelitian ini sebagai berikut: $=0,230+0,489+0,063+0,333+0,470=1,585$

\section{Diagam Jalur}

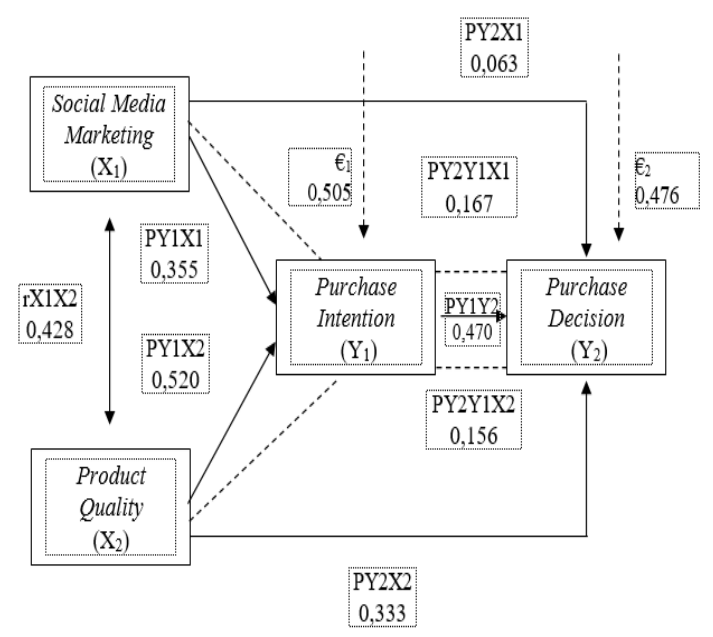

Gambar 6 Diagram Jalur

\section{Penutup dan Saran}

\section{Kesimpulan}

Berdasarkan hasil pembahasan analisis data yang melalui pembuktian terhadap hipotesis dari permasalahan yang diangkat mengenai faktor-faktor yang mempengaruhi purchase decision pada konsumen produk Jims Honey di Kabupaten Kebumen, maka dapat diperoleh kesimpulan sebagai berikut: 
1) Hasil penelitian menunjukan bahwa variabel social media marketing berpengaruh dan signifikan terhadap purchase intention pada konsumen produk Jims Honey di Kabupaten Kebumen.

2) Product quality berpengaruh signifikan terhadap purchase intention pada konsumen produk Jims Honey di Kabupaten Kebumen.

3) Social media marketing tidak berpengaruh terhadap purchase decision pada konsumen produk Jims Honey di Kabupaten Kebumen.

4) Product quality berpengaruh signifikan terhadap purchase decision pada konsumen produk Jims Honey di Kabupaten Kebumen.

5) Purchase intention berpengaruh signifikan terhadap purchase decision pada konsumen produk Jims Honey di Kabupaten Kebumen.

6) Variabel social media marketing berpengaruh secara tidak langsung terhadap purchase decision melalui purchase intention pada konsumen produk Jims Honey di Kabupaten Kebumen.

7) Variabel product quality berpengaruh secara tidak langsung terhadap purchase decision melalui purchase intention pada konsumen produk Jims Honey di Kabupaten Kebumen.

\section{Referensi}

Arifai, A. A., \& Trihandayani, Z. (2018). Harga, Kualitas Produk Dan Merek Terhadap Keputusan Pembelian Tas Kw Cartier Di Kalangan Mahasiswi Sebagai Penunjang Penampilan Kuliah. Jurnal Ilmiah Ekonomi Global Masa Kini, 8(3), 16-22.

Augusty Ferdinand. 2006. Metode Penelitian Manajemen :Pedoman Penelitian Untuk Penulisan Skripsi, Tesis, dan Disertasi Ilmu Manajemen. Semarang: Badan Penerbit Universitas Diponegoro.

DeMers, J. (2014). The top 10 benefits of social media marketing. Forbes. com, 11.

Dharmmesta, Basu Swastha dan Hani T Handoko.2012. Manajemen Pemasaran Analisis Perilaku Konsumen. Edisi Pertama. Cetakan Kelima. Yogyakarta : BPFE

Gunelius, S. (2011). 30 Minute Social Media Marketing. McGraw-Hill.

Ghozali, Imam. 2009.Aplikasi Analisis Multivariate dengan Program SPSS. Semarang: UNDIP.

Ghozali, Imam. 2013. Aplikasi Analisis Multivariate dengan Program IBM SPSS 21 Update PLS Regresi. Semarang: Badan Penerbit: Universitas Diponegoro.

Harsalim, R. R. (2015). Analisis Pengaruh Product Quality, Price Dan Promotion Terhadap Purchase Intention Mobil Toyota Alphard Di Surabaya. Jurnal Strategi Pemasaran, 3(1), 1-11.

Hoffman, D. L., Novak, T. P., \& Kang, H. (2017). Let's get closer: Feelings of connectedness from using social media, with implications for brand outcomes. Journal of the Association for Consumer Research, 2(2), 216-228.

Hosein, N. Z. (2012). Measuring the purchase intention of visitors to the auto show. Journal of management and marketing research, 9(1), 1-17. 
Karundeng, N., Kalangi, J. A., \& Walangitan, O. F. (2019). Pengaruh Kualitas Produk Terhadap Minat Beli Konsumen Pada Home Industri Pia Deisy Desa Kapitu Kecamatan Amurang Barat. JURNAL ADMINISTRASI BISNIS (JAB), 8(2), 83-90.

Kotler, Philip dan Kevin Lane Keller. 2012. Marketing Managemen.t Fourteenth Edition. New Jersey:Pearson Education.

Kotler, Philip and Kevin Lane Keller.2016.Marketing Managemet.Edisi 15 Global Edition. Pearson.

Mileva, L., \& Fauzi DH, A. (2018). Pengaruh Social Media Marketing Terhadap Keputusan Pembelian (Survei Online pada Mahasiswa Sarjana Jurusan Ilmu Administrasi Bisnis Angkatan 2014/2015 Fakultas Ilmu Administrasi Universitas Brawijaya yang Membeli Starbucks Menggunakan LINE). Jurnal Administrasi Bisnis, 58(1), 181-189.

Sumarwan, Ujang. 2014. Perilaku Konsumen : Teori dan Penerapannya dalam Pemasaran. Bogor: Ghalia Indonesia

Weenas, Jackson R.S. 2013. Kualitas Produk, Harga, Promosi dan Kualitas Pelayanan Pengaruhnya Terhadap Keputusan Pembelian Spring Bed Comforta. Jurnal EMBA, Vol. 1, No. 4, 2013. 607-618. 